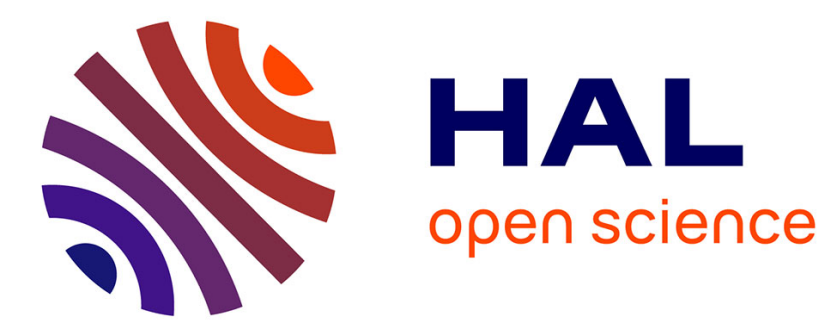

\title{
Ionized donor impurity in a semiconductor quantum well
}

B. Stébé, L. Stauffer, D. Fristot

\section{- To cite this version:}

B. Stébé, L. Stauffer, D. Fristot. Ionized donor impurity in a semiconductor quantum well. Journal de Physique IV Proceedings, 1993, 03 (C5), pp.C5-417-C5-420. 10.1051/.jp4:1993589 . jpa-00251676

\section{HAL Id: jpa-00251676 https://hal.science/jpa-00251676}

Submitted on 1 Jan 1993

HAL is a multi-disciplinary open access archive for the deposit and dissemination of scientific research documents, whether they are published or not. The documents may come from teaching and research institutions in France or abroad, or from public or private research centers.
L'archive ouverte pluridisciplinaire HAL, est destinée au dépôt et à la diffusion de documents scientifiques de niveau recherche, publiés ou non, émanant des établissements d'enseignement et de recherche français ou étrangers, des laboratoires publics ou privés. 


\title{
Ionized donor impurity in a semiconductor quantum well
}

\author{
B. STÉBÉ, L. STAUFFER* and D. FRISTOT
}

Univ. Metz, Supelec, Lab. Optoélectronique et Microélectronique, 1 Bd. Arago, 57078 Metz cedex 3, France

*Univ. Mulhouse, Lab. Phys. et Spectroscopie Electronique, 4 rue des Frères Lumière, 68093 Mulhouse cedex, France

\begin{abstract}
We present the results of a variational calculation of the ground state energy of a $\left(\mathrm{D}^{+}, \mathrm{X}\right)$ complex in a quantum well with finite potential barriers as a function of the depth and the width of the well as well as the ratio $\sigma$ of the electron and hole effective masses. We use the envelope function approximation. We apply our results to the system $\mathrm{GaAs} / \mathrm{Ga}_{1-x} A l_{x} \mathrm{As}$ with $\mathrm{x}=$ 0.15 and $x=0.30$. It appears that the coulombic correlation energy goes through a minimum for a well thickness in the order of 50 Angströms. This minimum is comprized between the values obtained in the 2D and 3D limit cases. Furthermore, it appears that only the heavy hole states give rise to a stable binding energy for all values of the well thickness. The light hole states give rise to stable binding only in the case of large thicknesses.
\end{abstract}

\section{INTRODUCTION}

The properties of excitons bound to neutral or ionized impurities have been extensively studied ${ }^{1,2}$ during the last years. They have been observed in many semiconductors since the early 1960 s. The bound exciton states are very common because most practical semiconductors contain in significant quantity impurities or defects which can produce this binding. The binding energy of the exciton to the impurity or defect is generally weak compared to the free-exciton binding energy. Moreover, it is now well known that if neutral centres should always exhibit a finite binding energy, ${ }^{3}$ the ionized donors or acceptors should only bind excitons under special circumstances.16 The recent advances in the crystal growth technique of molecular epitaxy allow the engineering of semiconductors on an atomic scale such as superlattices or quantum wells (QW's). ${ }^{5}$ In these heterostructures the quantum confinement effects may become important. In particular the coulombic interaction between electrons and holes is increased because the wave function is compressed along the growth-axis. Therefore excitonic effects become more important than in the bulk semiconductors and excitons may be observed up to room temperature because the thermal ionization is less efficient. 6,7 The same effect as well as an increasing of the oscillator strength ${ }^{8}$ is expected to occur in the case of excitons bound to neutral or ionized impurities. Recombinations due to intentionally introduced defects located in GaAs QW have been studied. ${ }^{9-12}$ There are only few theoretical studies concerning bound excitons. ${ }^{13,14}$ However, there does not exist, to our knowledge, any theory concerning the exciton-ionized-donor $\left(D^{+}, X\right)$ in $Q W^{\prime}$, though some transitions identified with this feature have been reported recently. ${ }^{15} \mathrm{Up}$ to now, only the limit-cases of doped bulk semiconductors, ${ }^{4}$ semiconductor surfaces ${ }^{16}$ or semi-3D infinite semiconductors ${ }^{17}$ have been considered theoretically. In particular, we have shown ${ }^{16}$ that the $2 \mathrm{D}\left(\mathrm{D}^{+}, \mathrm{X}\right)$-energies are about four times greater than those obtained in the $3 \mathrm{D}$ case. The energies in the $\mathrm{QW}$ are expected to be between the $2 \mathrm{D}$ and $3 \mathrm{D}$ limits.

In this paper, we report the results of a variational calculation of the energy of the $\left(D^{+}, X\right)$-complex in a single $\mathrm{QW}$ with finite conduction and valence band offsets. We consider a type I semiconductor QW with an jonized donor impurity localized at the centre of the well material that width is L. We suppose that the band offsets are weak enough so that the effective mass approximation may be used. Further, we assume isotropic parabolic non degenerated bands and same electron and hole effective 
masses in the well and the barrier materials.

\section{GROUND STATE ENERGY AND CONDITION OF STABILITY}

The Hamiltonian of an exciton bound to this impurity reads :

$$
\mathrm{H}=\mathrm{T}+\mathrm{V}_{\mathbf{c}}+\mathrm{V}_{\mathbf{w}}+\epsilon_{\mathrm{g}}
$$

where $\epsilon_{\mathrm{g}}$ corresponds to the well material energy-gap discontinuity between conduction and valence bands. $T, V_{c}$ and $V_{w}$ denote respectively the kinetic energy operator, the coulombic potential and the total well potential arising from the band of fset.

We obtain the ground state energy $\mathrm{E}$ and the enveloppe wave function $\psi$ as solutions of the effective Schrödinger equation :

$$
\left(\mathrm{H}-\epsilon_{\mathbf{g}}\right) \psi=\mathrm{E} \psi
$$

We choose the following trial wave function ${ }^{18}$ :

$$
\psi=f_{e}\left(z_{e}\right) f_{h}\left(z_{h}\right)\left(1+z_{e} z_{h}\right) \exp (-k s / 2) \sum_{\operatorname{lmn}} C_{l m n} s^{1} t^{m} u^{n}
$$

where $z_{e}$ and $z_{h}$ are the electron and hole coordinates along the $z$-axis which we assume to be parallel to the growth axis. $s, t$ and $u$ define the elliptic coordinates :

$$
\begin{aligned}
& \mathrm{s}=\rho_{\mathrm{e}}+\rho_{\mathrm{eh}}, \mathrm{t}=\rho_{\mathrm{e}}-\rho_{\mathrm{eh}}, \quad \mathrm{u}=\rho_{\mathrm{h}} \\
& 0 \leq \mathrm{s},-\mathrm{u} \leq \mathrm{t} \leq \mathrm{u}, 0 \leq \mathrm{u} \leq \mathrm{s}
\end{aligned}
$$

where $\rho_{\mathrm{e}}, \rho_{\mathrm{h}}$ and $\rho_{\mathrm{eh}}$ are the electron and hole coordinates in the plane perpendicular to the growth axis. 1, $\mathrm{m}, \mathrm{n}$ are positive integers or zero. The linear parameters $\mathrm{C}_{\mathrm{lmn}}$ as well as the scaling factor $\mathrm{k}$ are variational coefficients to be determined by minimizing the mean value of the total energy. The functions $f_{i}(i=e$, $h$ ) describe the ground states of an electron and a hole in square finite quantum wells of depth $V_{e}$ and $V_{h}$ respectively. This wave function, where the in-plane and $z$-coordinates are separated, is well adapted if the confinement energy is more important than the coulombic energy. In this case, we can replace the coulombic potential by its mean value over the in-plane part of the wave function. In the two limits where $\mathbf{L}$ becomes infinity or zero, our wave function becomes questionable because of the separation of the coordinates. However, in the case of infinite well depths and for very small values of $\mathrm{L}$, our function is expected to well describe this $2 \mathrm{D}$-limit. ${ }^{16}$

However, it must be stressed that the observation of the $\left(\mathrm{D}^{+}, \mathrm{X}\right)$-complex depends on its stability related to the condition : $E_{c} \leq E_{c}^{D}$ or $E \leq E^{D}+E_{h}$. To verify this inequation it is necessary to know the value of the total energy $E_{D}$ or the correlation energy $E_{c}^{D}=E^{D}-E_{e}$ of a neutral donor located at the centre of the well. Therefore we have performed a variational calculation of the correlation energy of donor impurity located at the centre of the well using the following wave function :

$$
\psi_{\mathrm{D}}=\mathrm{f}_{\mathrm{e}}\left(\mathrm{z}_{\mathrm{e}}\right)\left(1+\mathrm{z}_{\mathrm{e}}^{2}\right) \exp \left(-\alpha \rho_{\mathrm{e}}\right)
$$

where $\alpha$ is a variational parameter.

\section{RESULTS AND DISCUSSION}

We have calculated the energies $E_{c}$ as functions of $\sigma, L, V_{e}, V_{h}$ using 34 terms in the developpement of the trial wave function ( 3 ). In the present discussion, we apply our results to the case of $\mathrm{GaAs} / \mathrm{Ga}_{1-\mathrm{x}} \mathrm{Al}_{\mathrm{x}}$ As. We use the following material data ${ }^{19}: \mathrm{m}_{\mathrm{e}} / \mathrm{m}_{0}=0.0665$ for the electron mass, $\mathrm{m}_{\mathrm{hh}} / \mathrm{m}_{0}=0.34$ and $\mathrm{m}_{\mathrm{lh}} / \mathrm{m}_{0}=0.094$ for the heavy and light holes masses respectively. The band of fsets are given by $V_{e}=Q_{e} \epsilon_{g}$ and $V_{h}=Q_{h} \epsilon_{g}$ where $Q_{e}=0.57=1-Q_{h}$. Further we assume that the band gap $\epsilon_{\mathrm{g}}$ and the aluminium percentage $\mathrm{x}$ are related by ${ }^{20}: \epsilon_{\mathrm{g}}=1.155 \mathrm{x}+0.37 \mathrm{x}^{2} \mathrm{eV}$. Using the value $\mathrm{e}^{21} \epsilon=12.5$ 


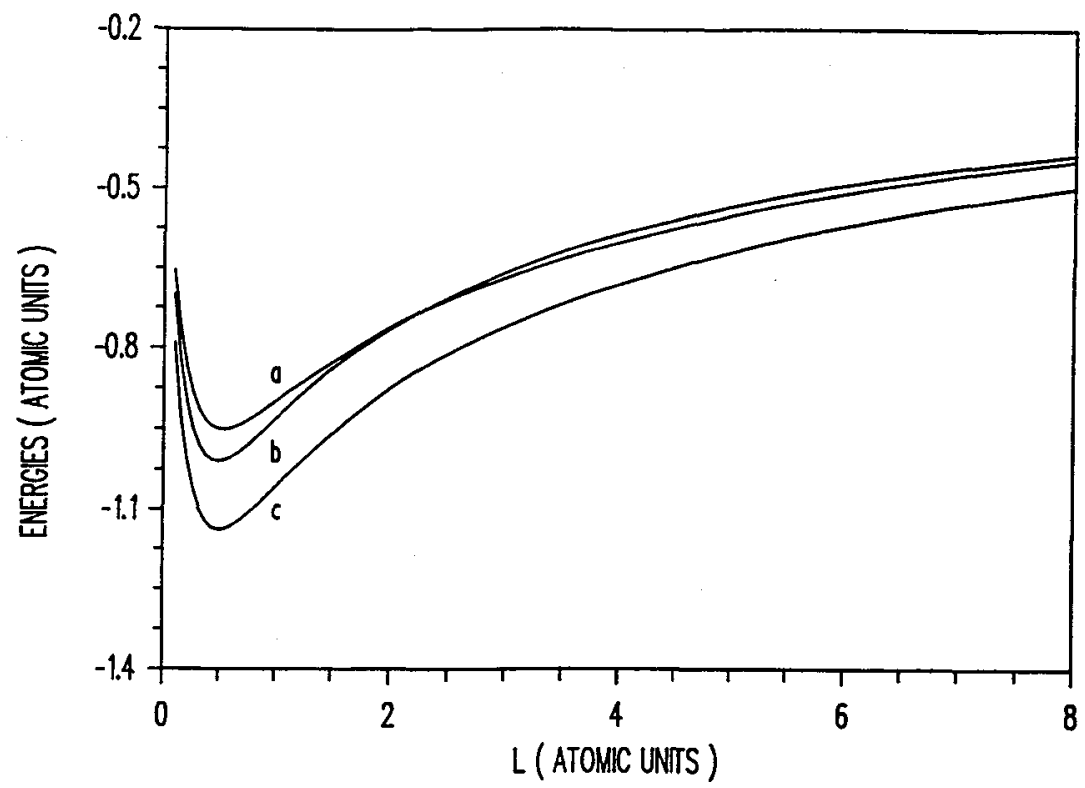

Figure 1: Variations of the coulombic correlation energy vs. the well width $L$ for a) light $(\sigma=.707)$ holes, b) donor impurity and c) heavy $(\sigma=.196)$ holes with $\mathrm{x}=.15$.

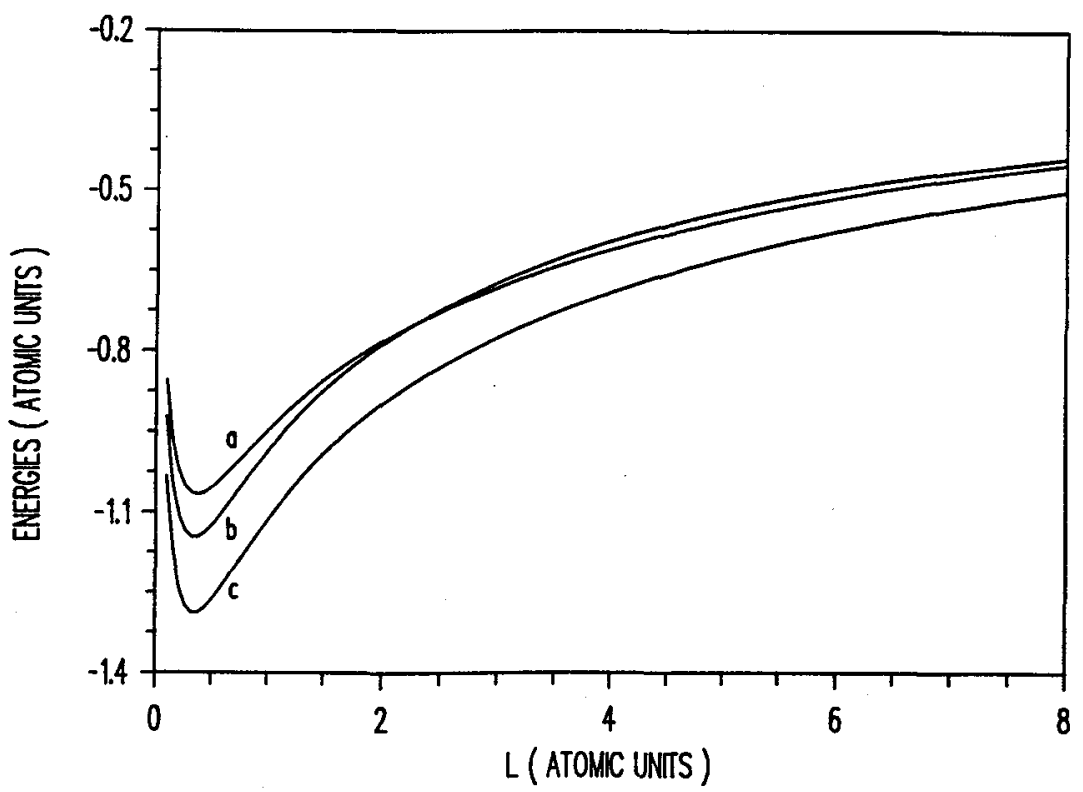

Figure 2: Variations of the coulombic correlation energy vs. the well width $L$ for a) light $(\sigma=.707)$ holes, $\mathrm{b})$ donor impurity and $c)$ heavy $(\sigma=.196)$ holes with $\mathrm{x}=.30$. 
for the dielectric constant, we get $a_{D}=\epsilon \hbar^{2} / m_{e} e^{2}=99.5$ Angströms for the effective Bohr radius and $2 R_{y}$ $=\mathrm{e}^{2} / \epsilon \mathrm{a}_{\mathrm{D}}=11.58 \mathrm{meV}$ for twice the effective ground state Rydberg of the 3D donor.

Curves a) and c) of Fig. 1 and 2 show the variations of the coulombic correlation energy $E_{c}$ vs. the well width $L$ for heavy $(\sigma=0.196)$ and light $(\sigma=0.707)$ holes, with $x=0.15$ and $x=0.30$. All the curves exhibit a pronounced mininimum for $L_{m} \simeq 50$ Angströms corresponding to a maximum of coulombic binding. In this case we expect the highest oscillator strengths. For $L>L_{m}, E_{c}$ is an increasing function of $\mathrm{L}$. When $\mathrm{L}$ tends to infinity, $\mathrm{E}_{\mathrm{c}}$ tends to the $3 \mathrm{D}$-limit ${ }^{16}$ corresponding to the given electron to hole effective mass ratio $\sigma$ whatever the values of $\mathrm{x}$. Nevertheless, our present values are slightly higher than our previous 3D results because our present wave function is not well adapted in this limit. We could improve these results by introducing more terms containing $z_{e}{ }^{p}$ or $z_{h}{ }^{q}$ in the developpement of the wave function $\psi$. For $\mathrm{L}<\mathrm{L}_{\mathrm{m}}, \mathrm{E}_{\mathrm{c}}$ decreases with $\mathrm{L}$. In this case, the probability of the formation of the $\left(\mathrm{D}^{+}, \mathrm{X}\right)$-complex becomes more and more weak due to the fact that the well behaves like a repulsive potential. In the limit where $L$ tends to zero, we get again the $3 D E_{c}$ values. The same result holds whatever the value of $L$ may be when $x$ tends to zero. Our results may be used to predict the positions of the lines associated with the formation of $a\left(\mathrm{D}^{+}, \mathrm{X}\right)$-complex. Indeed the transition energies are given by: $\mathrm{h} \nu=\epsilon_{\mathrm{g}}^{\prime}-\mathrm{E}_{\mathrm{c}}$, where $\epsilon_{\mathrm{g}}^{\prime}=\epsilon_{\mathrm{g}}+\mathrm{E}_{\mathrm{e}}+\mathrm{E}_{\mathrm{h}}$ is the gap corresponding the the confined particles in the well material. Curves b) of Fig. 1 and 2 show the variations of the donor correlation energies as a function of the well widths $\mathrm{L}$.

Our main result is that the heavy hole ionized bound exciton is stable for all values of $L$ if $x=0.15$ and $x=0.30$. However, the light hole bound exciton becomes unstable for $L<2.2$ at. units and $L<$ 2.1 at. units in the cases where $x=0.15$ and $x=0.30$ respectively.

Acknowledgements - This work has been performed at the Centre de Calcul de Strasbourg Cronenbourg (CNRS). It was supported by the Centre National de la Recherche Scientifique and the Ministère de l'Education Nationale ( DRED).

\section{References}

[1] P.J. Dean and D.C. Herbert, in Excitons, Vol. 14 of Topics in Current Physics, edited by K. Cho (Springer-Verlag, Berlin, 1979), p. 55.

[2] D.C. Reynolds and T.C. Collins, Excitons : Their Properties and Uses (Academic Press, New York, 1981).

[3] B. Stébé and G. Munschy, Solid State Commun. 35, 557 (1980).

[4] T. Skettrup, M. Suffczynski and W. Gorzkowski, Phys. Rev. B4, 512 (1971).

[5] L. Esaki, in Physics and Applications of Quantum Wells and Superlattices, edited by E.E. Mendez and K. von Klitzing, NATO ASI Series, Series B : Physics, Vol. 170 (Plenum Press, New York, 1987), p. 1.

[6] R.C. Miller, D.A. Kleinman, W.T. Tsang and A.C. Gossard, Phys. Rev. B24, 1134 (1981).

[7] G. Bastard, E.E. Mendez, L.L. Chang and L. Esaki, Phys. Rev. B26, 1974 (1982).

[8] D.C. Herbert and J.M. Rorison, Solid State Commun. 54, 343 (1985).

[9] R.C. Miller, A.C. Gossard, W.T. Tsang and O. Munteanu, Phys. Rev. B25, 3871 (1982).

[10] B. Lambert, B. Devaud, A. Regreny and G. Talalaeff, Solid State Commun. 43, 443 (1982).

[11] P.O. Holtz, M. Sundaram, J.L. Merz and A.C. Gossard, Phys. Rev. B40, 10021 (1989).

[12] J.P. Bergman, P.O. Holtz, B. Monemar, M. Sundaram, J.L. Merz and A.C. Gossard, Phys. Rev. B43, 4765 (1991).

[13] D.A. Kleinman, Phys. Rev. B28, 871 (1983).

[14] A. Haufe, Solid State Commun. 67, 899 (1988).

[15] D.C. Reynolds, C.E. Leak, K.K. Bajaj, C.E. Stutz, R.L. Jones, K.R. Evans, P.W. Yu and W.M. Theis, Phys. Rev. B40, 6210 (1989).

[16] L. Stauffer et B. Stébé, Phys. Rev. B39, 5345 (1989).

[17] G. Erzhen, S.W. Gu and B. Li, Phys. Rev. B42, 1258 (1990).

[18] L. Stauffer and B. Stébé, Solid State Communication 80, 983 (1991).

[19] R.C. Miller, D.A. Kleinman and A.C. Gossard, Phys. Rev. B29, 7085 (1984).

[20] H.J. Lee, L.Y. Juravel, J.C. Wolley and A.C. Springthorpe, Phys. Rev. B21, 659 (1980).

[21] R.L. Greene and K.K. Bajaj, Solid State Commun. 45, 825 (1983). 